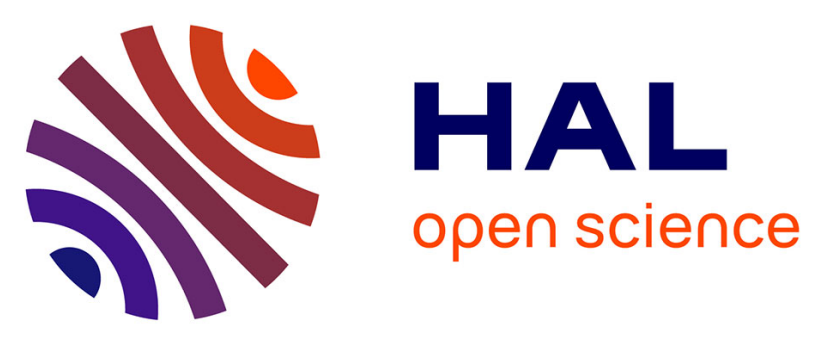

\title{
Absence of cardiac siderosis despite hepatic iron overload in Italian patients with thalassemia intermedia: an MRI T2* study
}

Alberto Roghi, Maria Domenica Cappellini, John C. Wood, Khaled M. Musallam, Pedrotti Patrizia, Maria Rosaria Fasulo, Claudia Cesaretti, Ali T. Taher

\section{To cite this version:}

Alberto Roghi, Maria Domenica Cappellini, John C. Wood, Khaled M. Musallam, Pedrotti Patrizia, et al.. Absence of cardiac siderosis despite hepatic iron overload in Italian patients with thalassemia intermedia: an MRI T2* study. Annals of Hematology, 2009, 89 (6), pp.585-589. 10.1007/s00277009-0879-3 . hal-00492779

\section{HAL Id: hal-00492779 \\ https://hal.science/hal-00492779}

Submitted on 17 Jun 2010

HAL is a multi-disciplinary open access archive for the deposit and dissemination of scientific research documents, whether they are published or not. The documents may come from teaching and research institutions in France or abroad, or from public or private research centers.
L'archive ouverte pluridisciplinaire HAL, est destinée au dépôt et à la diffusion de documents scientifiques de niveau recherche, publiés ou non, émanant des établissements d'enseignement et de recherche français ou étrangers, des laboratoires publics ou privés. 


\section{Editorial Manager(tm) for Annals of Hematology}

Manuscript Draft

\section{Manuscript Number: AOHE-D-09-00451R1}

Title: Absence of cardiac siderosis despite hepatic iron overload in Italian patients with thalassemia intermedia: an MRI T2* study

Article Type: Original Article

Keywords: thalassemia intermedia; iron overload; heart; liver; magnetic resonance imaging

Corresponding Author: Prof. Maria D Cappellini, MD

Corresponding Author's Institution:

First Author: Alberto Roghi

Order of Authors: Alberto Roghi; Maria D Cappellini, MD; John C Wood; Khaled M Musallam; Pedrotti Patrizia; Maria R Fasulo; Claudia Cesaretti; Ali T Taher

Abstract: Cardiac involvement in patients with thalassemia intermedia (TI) is characterized by a highoutput state and pulmonary hypertension, with systolic left ventricle function usually being preserved. Myocardial iron overload in patients with TI has not been extensively studied. We conducted a crosssectional study of 49 Italian patients with TI. Patient charts were reviewed and data collected for transfusion and iron chelation history, status of the spleen, and comorbid illnesses or infections. Blood samples were obtained for assessment of hemoglobin, serum ferritin and liver enzyme levels. Doppler echocardiography was done for all patients. Cardiac and hepatic iron levels were measured by MRI T2*. The mean age was $40.5 \pm 8.3$ years, with a male to female ratio of 29:20. A total of $34(69.4 \%)$ patients were splenectomized and 4 patients had evidence of hepatitis $C$ infection. Around $45 \%$ of patients were transfusion naïve while the rest received infrequent (47\%) or regular (8\%) transfusions. A total of $31(63.3 \%)$ patients were maintained on iron chelation therapy. None of the patients had evidence of heart failure. Mean serum ferritin and liver iron concentration were $1060.2 \mathrm{ng} / \mathrm{ml}$ and $8.2 \mathrm{mg} \mathrm{Fe} / \mathrm{g}$ dry weight; respectively. None of the patients had evidence of cardiac iron overload (mean cardiac T2* $=38.7 \pm 11.0 \mathrm{~ms}$ ). There were no statistically significant correlation between cardiac $\mathrm{T} 2 *$ values and liver iron concentration; serum ferritin; or any patient, disease or treatment related parameters. Patients with TI show absence of cardiac iron overload even if hepatic iron accumulation is significant.

\section{Response to Reviewers: RESPONSE TO REVIEWER COMMENTS}

"This is a well-written report on the abscence of cardiac iron overload in patients with TI. Since it is a cross-sectional analysis, it is important to exclude any selection pocedures whenever possible. Thus, the question which has to be answered by the authors is how patients were selected. This has to be carefully described in the methods section. The reader would like to know how many patients were eligible and how many were actually studied and why selection occurred."

We thank the reviewer for this note, the selection criteria was only based on age. In this study we only recruited adult ( $\geq 18$ years) patients, to avoid the need for sedation to complete the MRI in children. So, out of 124 patients registered at the center, 49 were adults and hence all included in the study. This is now clearly explained in the first paragraph of the METHODS section. 
"Another question to be answered is the dosage of iron chelators used."

Patients who were maintained on subcutaneous deferoxamine regimens received 20-60 mg/kg for 12 hours a day, three days a week; while patients who received the oral iron chelator deferasirox received $15-20 \mathrm{mg} / \mathrm{kg} /$ day. This was added to the first paragraph of the RESULTS section. 


\section{ORIGINAL ARTICLE}

\section{Absence of cardiac siderosis despite hepatic iron overload in Italian patients with thalassemia intermedia: an MRI T2* study}

Short title: cardiac iron in thalassemia intermedia

Alberto Roghi, ${ }^{1}$ Maria Domenica Cappellini, ${ }^{2 *}$ John C. Wood, ${ }^{3}$ Khaled M. Musallam, ${ }^{4}$ Pedrotti Patrizia, ${ }^{1}$ Maria Rosaria Fasulo, ${ }^{2}$ Claudia Cesaretti, ${ }^{2}$ and Ali T. Taher ${ }^{4}$

${ }^{1}$ Cardiac MR Unit, De Gasperis' Department of Cardiology, Niguarda Ca' Granda Hospital, Milan, Italy

${ }^{2}$ Universitá di Milano, Policlinico Foundation IRCCS, Milan, Italy

${ }^{3}$ Divisions of Pediatric Cardiology and Radiology, Children's Hospital Los Angeles and Keck School of Medicine, University of Southern California, Los Angeles, USA

${ }^{4}$ Department of Internal Medicine, Hematology-Oncology Division, American University of Beirut Medical Center, Beirut, Lebanon

\section{*Correspondence}

Maria Domenica Cappellini, MD

Professor of Medicine

Universitá di Milano, Fondazione Ospedale Maggiore Policlinico

Mangiagalli, Regina Elena IRCCS

Milan, Italy

Tel: +39 347788 5455; Fax: +39 347788 5455; E-mail: maria.cappellini@unimi.it 


\begin{abstract}
Cardiac involvement in patients with thalassemia intermedia (TI) is characterized by a highoutput state and pulmonary hypertension, with systolic left ventricle function usually being preserved. Myocardial iron overload in patients with TI has not been extensively studied. We conducted a cross-sectional study of 49 Italian patients with TI. Patient charts were reviewed and data collected for transfusion and iron chelation history, status of the spleen, and comorbid illnesses or infections. Blood samples were obtained for assessment of hemoglobin, serum ferritin and liver enzyme levels. Doppler echocardiography was done for all patients. Cardiac and hepatic iron levels were measured by MRI T2*. The mean age was $40.5 \pm 8.3$ years, with a male to female ratio of 29:20. A total of $34(69.4 \%)$ patients were splenectomized and 4 patients had evidence of hepatitis C infection. Around $45 \%$ of patients were transfusion naïve while the rest received infrequent $(47 \%)$ or regular $(8 \%)$ transfusions. A total of $31(63.3 \%)$ patients were maintained on iron chelation therapy. None of the patients had evidence of heart failure. Mean serum ferritin and liver iron concentration were $1060.2 \mathrm{ng} / \mathrm{ml}$ and $8.2 \mathrm{mg} \mathrm{Fe} / \mathrm{g}$ dry weight; respectively. None of the patients had evidence of cardiac iron overload (mean cardiac $\mathrm{T} 2 *=38.7 \pm 11.0 \mathrm{~ms}$ ). There were no statistically significant correlation between cardiac $\mathrm{T} 2 *$ values and liver iron concentration; serum ferritin; or any patient, disease or treatment related parameters. Patients with TI show absence of cardiac iron overload even if hepatic iron accumulation is significant.
\end{abstract}

Keywords: thalassemia intermedia; iron overload; heart; liver; magnetic resonance imaging. 


\section{Introduction}

In contrast to thalassemia major (TM), patients with thalassemia intermedia (TI) often have mild anemia that generally does not require regular blood transfusion therapy until later in life. However, TI patients remain at risk of the clinical sequelae of iron overload, primarily due to increased intestinal iron absorption and ineffective erythropoiesis [1]. Heart disease is the primary cause of death in TM, with myocardial iron loading observed in approximately two-thirds of patients receiving iron chelation therapy [2]. In TI, cardiac involvement is mainly characterized by a high-output state and pulmonary hypertension, with systolic left ventricle function usually being preserved [3, 4]. Myocardial iron overload in patients with TI has not been extensively studied; however, a recent report has shown no evidence of cardiac iron in a small group $(n=20)$ of patients [5]. The current study aims to further evaluate cardiac iron overload in a larger group of TI patients, and explore its correlation with liver iron concentration (LIC) and serum ferritin (SF) levels among other patient and disease characteristics.

\section{Materials and methods}

This was a cross-sectional study of adult ( $\geq \mathbf{1 8}$ years) patients with TI treated at the Centro Anemie Congenite, Ospedale Maggiore Policlinico, IRCCS, University of Milan, Milan, Italy. All patients were diagnosed with TI based on criteria previously described $[6,7]$. This study recruited adult patients only, to avoid the need for sedation to complete the magnetic resonance imaging (MRI) in children. Out of a cohort of 124 patients registered at the center, 49 adults ( $\geq 18$ years) were identified. Patient charts were reviewed for data on patient's demographics (age and gender); splenectomy status; presence of comorbid illnesses or infections; and history of transfusion and iron chelation therapy. For transfusion status, patients were divided as follows: regularly transfused (2-4 times per year); 
infrequently transfused (few transfusions received in the past); and transfusion naïve. Iron chelation therapy had to be administered for at least one year or else the patient was considered non-chelated. Written informed consent was provided by all patients and approval was obtained from the ethical committee at the center.

\section{Laboratory tests}

Blood samples were obtained for assessment of pre-transfusion hemoglobin $(\mathrm{Hb})$, steadystate SF, and alanine transaminase (ALT) levels.

\section{Echocardiography}

Doppler echocardiography to assess left ventricular ejection fraction (LVEF) was done.

\section{Magnetic resonance imaging}

Cardiac iron levels were measured by MRI T2*. Patients were scanned with MRI $1.5 \mathrm{~T}$ Magnetom Avanto Siemens using a multiecho breath-hold sequence [echo times (TE) 2.58$18.9 \mathrm{~ms}$ ] as described by Wood JC [8]. In this study, cardiac T2* $>20 \mathrm{~ms}$ was considered normal. LIC was calculated from liver T2* images [TE 0.99-16.50 ms] according to the formula $[1 /(\mathrm{T} 2 * / 1000)] \times 0.0254+0.202]$ [9]. All $\mathrm{T} 2 *$ images were analyzed using postprocessing software (CMR Tools, Imperial College, London).

\section{Statistical analysis}

Data are expressed as means \pm standard deviation (SD) or percentages where appropriate. All univariate comparisons between iron overload parameters (SF, LIC, and cardiac T2*) and continuous variables (age, $\mathrm{Hb}, \mathrm{LVEF}, \mathrm{ALT})$ were evaluated using Spearman's $\left(r_{\mathrm{s}}\right)$ correlation coefficients. Comparisons with categorical variables (gender, splenectomy, transfusion, and chelation status) were evaluated using the independent samples $t$-test and ANOVA test. A multivariate stepwise regression analysis was done to determine significant correlations. Linear regression analysis was performed to study correlations between SF, LIC, ALT and 
cardiac R2* values $(\mathrm{R} 2 *=1000 / \mathrm{T} 2 *)$. All $P$-values are two sided with the level of significance set at $<0.05$.

\section{Results}

Data from 49 patients were included in this analysis (Table 1). A total of four patients had evidence of hepatitis $\mathrm{C}$ virus (HCV) infection confirmed by PCR-RNA testing. Among patients who received iron chelation therapy, 29 (93.5\%) were maintained on subcutaneous

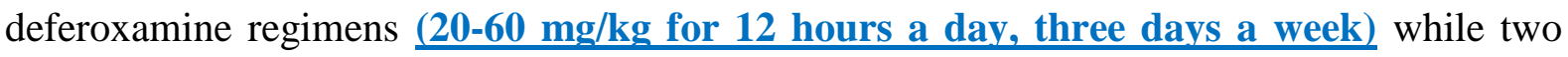
(6.5\%) received the oral iron chelator deferasirox once daily $(\mathbf{1 5 - 2 0} \mathrm{mg} / \mathrm{kg} / \mathrm{day})$. No patient had evidence of heart failure by modified Framingham criteria [10].

The mean \pm SD of SF levels and LIC were $1060.2 \pm 1090.3 \mathrm{ng} / \mathrm{ml}($ range: $165-6361 \mathrm{ng} / \mathrm{ml})$ and $8.2 \pm 6.0 \mathrm{mg} \mathrm{Fe} / \mathrm{g}$ dry weight (dw) (range: 1.1-26.4 mg Fe/g dw); respectively. None of the patients had evidence of cardiac iron overload (mean cardiac $\mathrm{T} 2 *=38.7 \pm 11.0 \mathrm{~ms}$; range: $22.4-82.4 \mathrm{~ms})$. On linear regression analysis, there were no statistically significant correlations between cardiac R2* and LIC $\left(R^{2}=0.007 ; p=0.569\right.$; Fig. 1$)$ or SF $\left(R^{2}=0.003\right.$; $P=0.716)$. There was a statistically significant positive correlation between SF and LIC but with poor linearity $\left(R^{2}=0.435 ; P=<0.001\right)$.

SF levels were significantly higher in splenectomized, regularly transfused and chelated patients; and correlated positively with ALT levels (Table 2). On multivariate analysis only ALT levels retained correlation with SF levels $(P<0.001)$. Similarly, LIC values were only significantly positively correlated with ALT levels (Table 2). However, ALT levels did not rise linearly with SF $\left(R^{2}=0.371\right)$ or LIC $\left(R^{2}=0.127\right)$. There was no statistically significant correlation between cardiac T2* values and any of the study parameters (Table 2).

Of note, there was no statistically significant differences between HCV positive and negative patients with regards to SF $(P=522)$, LIC $(P=603)$, or cardiac T2* $(P=534)$; however, 
HCV positive patients had higher mean ALT levels than HCV negative patients (58.8 vs. 34.1 IU/L; $P=0.043)$

\section{Discussion}

Data from this cross-sectional study show absence of cardiac iron overload in patients with TI, despite significant hepatic iron accumulation ( $>7 \mathrm{mg} \mathrm{Fe} / \mathrm{g} \mathrm{dw}$ ), thus providing additional insight to aid our understanding of iron deposition in this patient group.

These data, which show cardiac $\mathrm{T} 2 *$ within the normal range in all patients, support other recent findings in which cardiac $\mathrm{T} 2 *$ was $>20 \mathrm{~ms}$ in 20 never or minimally transfused TI patients despite elevated LIC [5]. Furthermore, they are consistent with studies showing that patients with TI are generally less prone to the cardiac iron overload associated with morbidity and mortality than patients with TM [4]. However, they contrast with other reports indicating moderate cardiac iron overload in subgroups of TI patients $[11,12]$. The varying results might be explained by differences in baseline characteristics (eg, previous transfusion history and co-pathology) between patient populations.

In $\mathrm{TI}$, the combination of ineffective erythropoiesis and chronic anemia/hypoxia result in hepcidin suppression, increased intestinal iron absorption and increased release of recycled iron from the reticuloendothelial (RE) system (macrophages) to the hepatocytes [1, 13, 14]. This explains the relatively low levels of SF yet high LIC (regardless of transfusion history); and confirms that SF underestimates iron burden in TI with poor correlation with LIC [15, 16]. By contrast, in transfused TM patients iron is preferentially distributed to the RE system, stimulating SF synthesis and its release to the circulation [15]. The effect of this disparity in the pathophysiology of iron overload on cardiac sparing in TI patients, and the probability of eventual cardiac iron overload with continuous transfusion therapy merits consideration in long-term follow up studies. 
In fact, the relationship between cardiac $\mathrm{T} 2 *$ values and iron balance is quite complicated because the mechanisms and kinetics of cardiac iron uptake and clearance differ from the liver $[17,18]$. The lack of correlation between cardiac T2* and LIC or SF in the current study is consistent with data from a previous study on TI patients in which the authors found no correlation between cardiac T2* and SF values [5]. Data from animal models of iron overload in TI also indicate early accumulation of iron in the liver, with accumulation of iron in the heart occurring over longer periods [19]. Studies on patients with TM and sickle cell disease (SCD), confirm that cardiac T2* values do not correlate with SF concentration and LIC in cross sectional analysis, while longitudinal studies continue to imply a causal relationship $[12,17,18,20-22]$. Wood and Noetzli $[17,20]$, demonstrated a significant latency to cardiac $\mathrm{T} 2 *$ changes, relative to liver accumulation, suggesting a long delay between poor iron control and detectable cardiac iron deposition. Other MRI work suggests that a "critical" liver saturation is necessary to achieve positive cardiac iron balance [23]. This may explain absence of cardiac iron overload even in patients who had LIC $>15 \mathrm{mg} \mathrm{Fe} / \mathrm{g} \mathrm{dw}$ in this study. In conclusion, in patients with TI who had or had not received previous transfusion therapy we found no evidence of cardiac iron overload although hepatic iron accumulation was significant. Further research is needed to better understand if (and when) detectable cardiac iron deposition can occur in patients with TI. Data also confirm that SF levels do not accurately reflect the level of iron overload. Thus, recommendations for the management of patients with TI should include regular assessment of LIC via biopsy or non-invasive imaging methods, with iron chelation therapy being initiated in patients with LIC levels indicating liver iron overload.

\section{Conflict of Interest}

MDC and ATT are members of Novartis Speakers' Bureau. JCW received research funding from Novartis Pharmaceuticals. 


\section{Funding}

This study was supported by an unrestricted grant from Novartis Pharmaceuticals. $\underline{\text { This }}$ study did not receive external funding. 


\section{References}

1. Origa R, Galanello R, Ganz T, Giagu N, Maccioni L, Faa G, Nemeth E (2007) Liver iron concentrations and urinary hepcidin in $\beta$-thalassemia. Haematologica 92:583-588

2. Tanner MA, Galanello R, Dessi C, Westwood MA, Smith GC, Nair SV, Anderson LJ, Walker JM, Pennell DJ (2006) Myocardial iron loading in patients with thalassemia major on deferoxamine chelation. J Cardiovasc Magn Reson 8:543-547

3. Aessopos A, Farmakis D, Deftereos S, Tsironi M, Tassiopoulos S, Moyssakis I, Karagiorga M (2005) Thalassemia heart disease: a comparative evaluation of thalassemia major and thalassemia intermedia. Chest 127:1523-1530

4. Aessopos A, Kati M, Farmakis D (2007) Heart disease in thalassemia intermedia: a review of the underlying pathophysiology. Haematologica 92:658-665

5. Origa R, Barella S, Argiolas GM, Bina P, Agus A, Galanello R (2008) No evidence of cardiac iron in 20 never or minimally transfused patients with thalassemia intermedia. Haematologica 93:1095-1096

6. Camaschella C, Cappellini MD. Thalassemia intermedia. Haematologica 1995;80:5868

7. Cappellini MD, Musallam KM, Cesaretti C, Taher A. Chapter 12: Thalassemia intermedia. Disorders of iron homeostasis, erythrocytes, erythropoiesis. ESH/Club du Globule Rouge et du Fer Handbook, 2009

8. Wood JC (2007) Magnetic resonance imaging measurement of iron overload. Curr Opin Hematol 14:183-190

9. Wood JC, Enriquez C, Ghugre N, Tyzka JM, Carson S, Nelson MD, Coates TD (2005) MRI R2 and R2* mapping accurately estimates hepatic iron concentration in transfusion-dependent thalassemia and sickle cell disease patients. Blood 106:14601465 
10. Kleber FX, Niemoller L, Doering W (1992) Impact of converting enzyme inhibition on progression of chronic heart failure: results of the Munich mild heart failure trial. Br Heart J 67:289-296

11. Pepe A, Cracolici E, Santarelli MF, Sorrentino F, Cracolici E, De Marchi D et al (2006) Cardiac magnetic resonance characterization of thalassemia intermedia patients confronted with TM patients. J Am Coll Cardiol 47:136

12. Voskaridou E, Douskou M, Terpos E, Papassotiriou I, Stamoulakatou A, Ourailidis A, Loutradi A, Loukopoulos D (2004) Magnetic resonance imaging in the evaluation of iron overload in patients with beta thalassaemia and sickle cell disease. Br J Haematol $126: 736-742$

13. Tanno T, Bhanu NV, Oneal PA, Goh S-H, Staker P, LeeYT, Moroney JW, Reed CH, Luban NL, Wang R-H, Eling TE, Childs R, Ganz T, Leitman SF, Fucharoen S, Miller JL (2007) High levels of GDF15 in thalassemia suppress expression of the iron regulatory protein hepcidin. Nat Med 13:1096-1101

14. Silvestri L, Pagani A, Camaschella C (2008) Furin-mediated release of soluble hemojuvelin: a new link between hypoxia and iron homeostasis. Blood 111:924-931

15. Pakbaz Z, Fischer R, Fung E, Nielsen P, Harmatz P, Vichinsky E (2007) Serum ferritin underestimates liver iron concentration in transfusion independent thalassemia patients as compared to regularly transfused thalassemia and sickle cell patients. Pediatr Blood Cancer 49:329-332

16. Taher A, El Rassi F, Isma'eel H, Koussa S, Inati A, Cappellini MD (2008) Correlation of liver iron concentration determined by $\mathrm{R} 2$ magnetic resonance imaging with serum ferritin in patients with thalassemia intermedia. Haematologica 93:1584-1586

17. Noetzli LJ, Carson SM, Nord AS, Coates TD, Wood JC (2008) Longitudinal analysis of heart and liver iron in thalassemia major. Blood 112: 2973-2978 
18. Anderson LJ, Holden S, Davis B, Prescott E, Charrier CC, Bunce NH, Firmin DN, Wonke B, Porter J, Walker JM, Pennell DJ (2001) Cardiovascular T2-star (T2*) magnetic resonance for the early diagnosis of myocardial iron overload. Eur Heart $\mathbf{J}$ 22: $2171-2179$

19. Gardenghi S, Marongiu MF, Ramos P, Guy E, Breda L, Chadburn A, Liu Y, Amariglio N, Rechavi G, Rachmilewitz EA, Breuer W, Cabantchik ZI, Wrighting DM, Andrews NC, de Sousa M, Giardina PJ, Grady RW, Rivella S (2007) Ineffective erythropoiesis in $\beta$-thalassemia is characterized by increased iron absorption mediated by down-regulation of hepcidin and up-regulation of ferroportin. Blood 109:50275035

20. Wood JC, Tyszka JM, Carson S, Nelson MD, Coates TD (2004) Myocardial iron loading in transfusion-dependent thalassemia and sickle cell disease. Blood 103:19341936

21. Raman SV, Simonetti OP, Cataland SR, Kraut EH (2006) Myocardial ischemia and right ventricular dysfunction in adult patients with sickle cell disease. Haematologica 91:1329-1335

22. Inati A, Musallam KM, Wood JC, Sheikh-Taha M, Daou L, Taher AT (2009) Absence of cardiac siderosis by MRI T2* despite transfusion burden, hepatic and serum iron overload in Lebanese patients with sickle cell disease. Eur J Haematol. doi:10.1111/j.1600-0609.2009.01345.x

23. Jensen PD, Jensen FT, Christensen T, Eiskjaer H, Baandrup U, Nielsen JL (2003) Evaluation of myocardial iron by magnetic resonance imaging during iron chelation therapy with deferrioxamine: indication of close relation between myocardial iron content and chelatable iron pool. Blood 101:4632-4639 
Table 1 Patients' characteristics

\section{Value}

$40.5 \pm 8.3(23-64)$

$29 / 20$

$34(69.4)$

Transfusion status, n (\%)

Nä̈ve

$22(44.9)$

Infrequent

$23(46.9)$

Regular

$4(8.2)$

Chelation received, $\mathrm{n}(\%)$

$31(63.3)$

Mean $\mathrm{ALT} \pm \mathrm{SD}, \mathrm{IU} / \mathrm{L}$ (range)

$36.2 \pm 23.5(9-91)$

Mean $\mathrm{Hb} \pm \mathrm{SD}, \mathrm{g} / \mathrm{dL}$ (range)

$8.8 \pm 1.5(5.3-13.1)$

Mean LVEF $\pm \mathrm{SD}, \%$ (range)

$\mathrm{ALT}=$ alanine transaminase $\mathrm{Hb}=$ hemoglobin $; \mathrm{LVEF}=$ left ventricular ejection fraction. 
Table 2 Univariate analysis showing correlations between study variables and iron overload parameters

\begin{tabular}{|c|c|c|c|}
\hline Variable & $\begin{array}{l}\mathbf{S F} \\
(\mathrm{ng} / \mathrm{mL})\end{array}$ & $\begin{array}{l}\text { LIC } \\
\text { (mg Fe/g dry weight) }\end{array}$ & $\begin{array}{l}\text { Cardiac T2* } \\
(\mathrm{ms})\end{array}$ \\
\hline \multicolumn{4}{|l|}{ Categorical $^{\mathrm{a}}$} \\
\hline \multicolumn{4}{|l|}{ Gender } \\
\hline Male $(\mathrm{n}=29)$ & $1132.9 \pm 1285.9$ & $7.6 \pm 5.8$ & $40.8 \pm 11.8$ \\
\hline Female $(n=20)$ & $943 \pm 685.3$ & $9.2 \pm 6.4$ & $35.6 \pm 9.3$ \\
\hline$P$-value & 0.567 & 0.375 & 0.107 \\
\hline \multicolumn{4}{|l|}{ Splenectomy } \\
\hline Yes $(n=34)$ & $1264.1 \pm 1235.4$ & $8.5 \pm 5.9$ & $40.2 \pm 12.5$ \\
\hline No $(n=15)$ & $579.4 \pm 308.2$ & $7.7 \pm 6.6$ & $35.3 \pm 5.9$ \\
\hline$P$-value & 0.048 & 0.691 & 0.157 \\
\hline \multicolumn{4}{|l|}{ Transfusion status } \\
\hline Naïve $(\mathrm{n}=22)$ & $642.3 \pm 685.3$ & $6.3 \pm 5.0$ & $37.4 \pm 5.9$ \\
\hline Infrequent $(n=23)$ & $1341.7 \pm 1265.0$ & $10.0 \pm 6.7$ & $41.1 \pm 14.5$ \\
\hline Regular $(n=4)$ & $1826.3 \pm 1191.0$ & $9.1 \pm 5.8$ & $32.4 \pm 6.7$ \\
\hline$P$-value & 0.044 & 0.115 & 0.270 \\
\hline \multicolumn{4}{|l|}{ Iron chelation } \\
\hline Yes $(n=31)$ & $1313.8 \pm 1233.8$ & $9.1 \pm 6.5$ & $38.9 \pm 11.8$ \\
\hline No $(n=18)$ & $612.5 \pm 570.0$ & $7.7 \pm 6.6$ & $38.4 \pm 10.0$ \\
\hline$P$-value & 0.033 & 0.220 & 0.895 \\
\hline
\end{tabular}

\begin{tabular}{|c|c|c|c|}
\hline \multicolumn{4}{|l|}{ Continuous $^{\mathrm{b}}$} \\
\hline Age (years) & 0.2 & -0.023 & -0.196 \\
\hline$P$-value & 0.178 & 0.878 & 0.177 \\
\hline $\mathbf{H b}(\mathrm{g} / \mathrm{dL})$ & -0.103 & -0.129 & 0.003 \\
\hline$P$-value & 0.489 & 0.377 & 0.986 \\
\hline $\mathbf{A L T}^{\mathbf{c}}(\mathrm{IU} / \mathrm{L})$ & 0.600 & 0.421 & -0.039 \\
\hline$P$-value & $<0.001$ & 0.004 & 0.801 \\
\hline LVEF (\%) & 0.109 & -0.129 & 0.003 \\
\hline$P$-value & 0.464 & 0.377 & 0.986 \\
\hline \multicolumn{4}{|c|}{$\begin{array}{l}\mathrm{SF}=\text { serum ferritin; } \mathrm{LIC}=\text { liver iron concentration; } \mathrm{Hb}=\text { hemoglobin; } \mathrm{ALT}=\text { alanine transaminase } ; \mathrm{LVEF}=\text { left } \\
\text { ventricular ejection fraction. }\end{array}$} \\
\hline
\end{tabular}


Fig. 1 Correlation between liver iron concentration (LIC) and cardiac R2* values

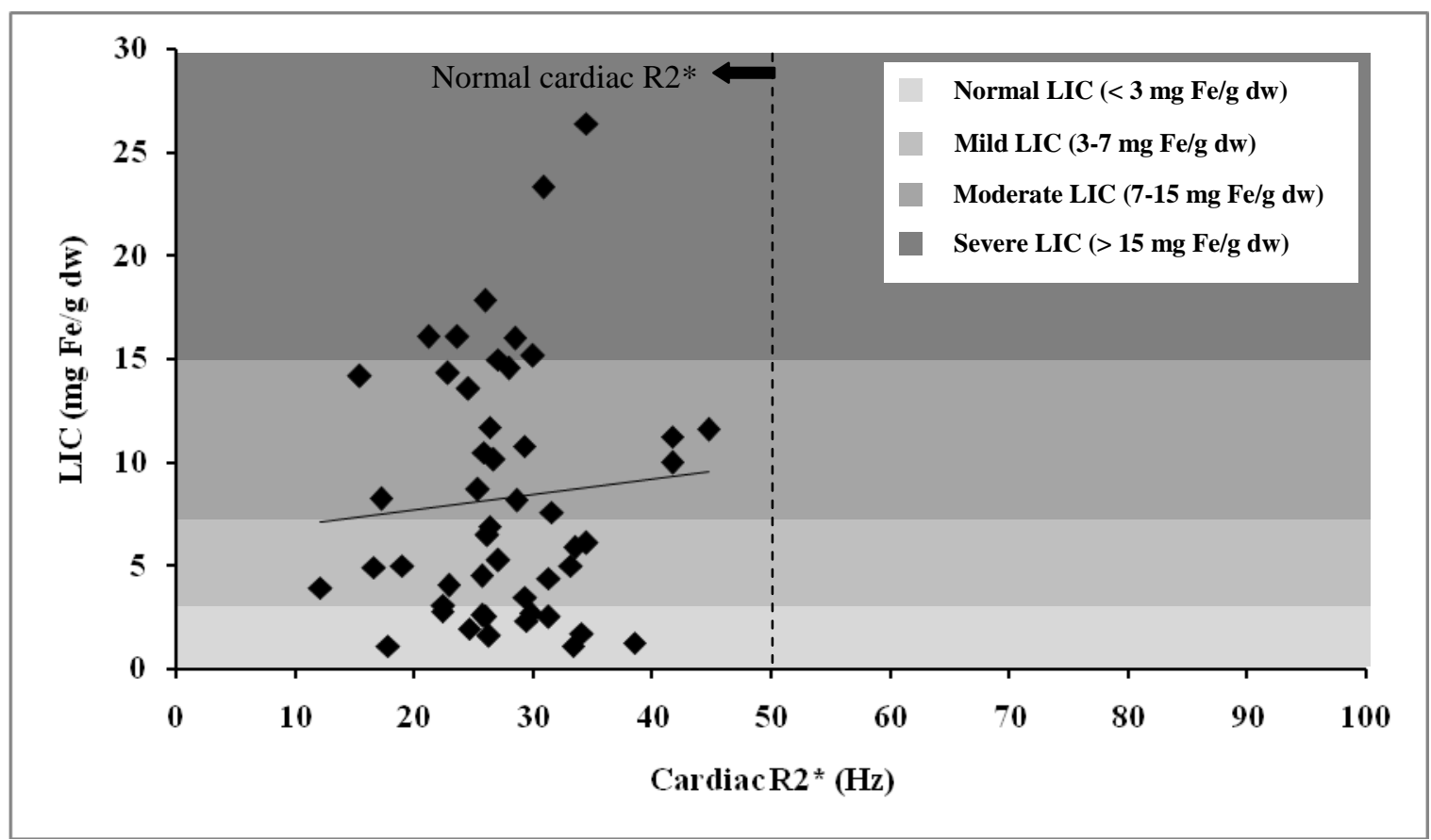


Conflict of interest
Click here to download Conflict of interest: COI.pdf

Conflict of interest
Click here to download Conflict of interest: COI.pdf Click here

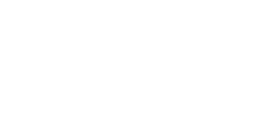

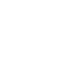

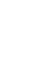

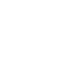

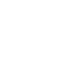

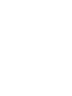
(n)

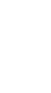

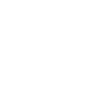

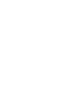

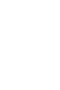

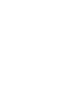

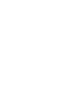
(1)

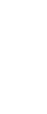

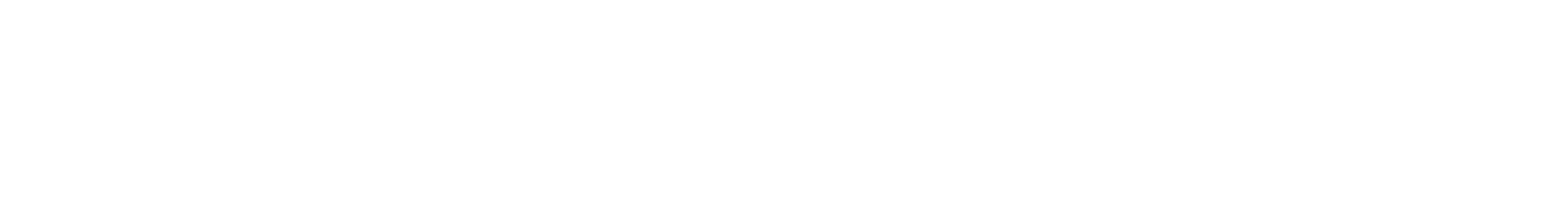

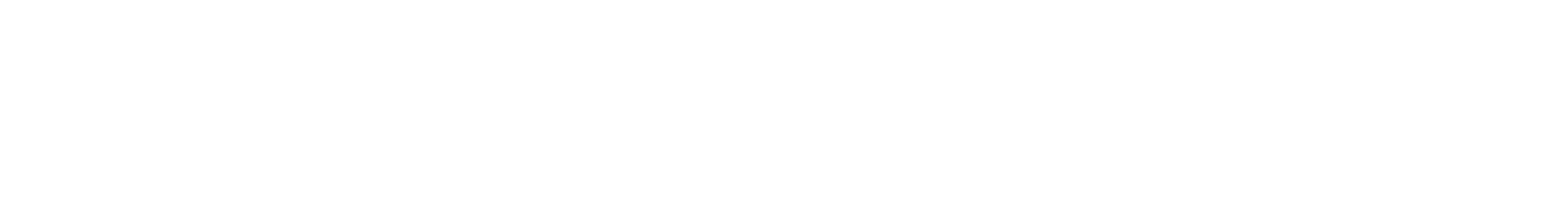

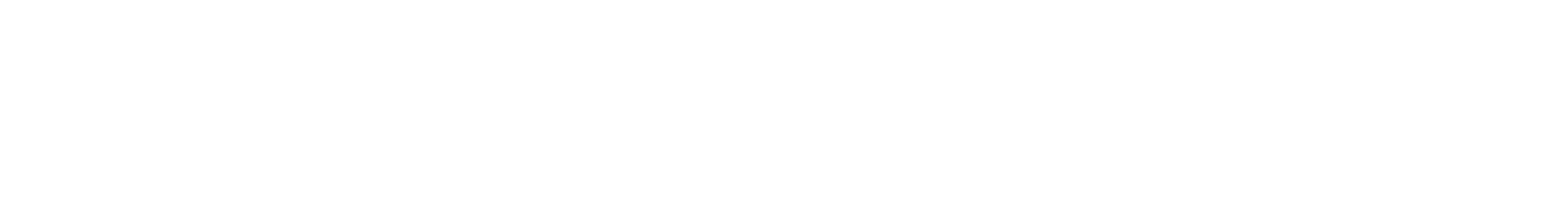
(n) (n) (n) (n) (n) (n) (n) (n) (n) (n) (1)

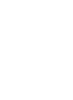
(

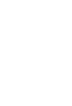

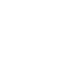

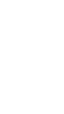

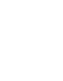

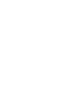

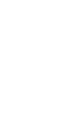
(1)

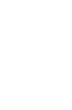

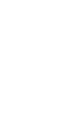

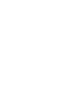

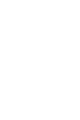

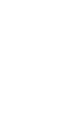

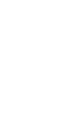

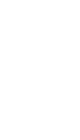

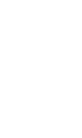

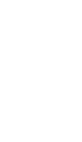

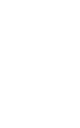


Manuscript clean
Click here to down

Click here to download Supplementary Material: MANUSCRIPT_Clean.doc

\begin{abstract}
Click here to download Supplementary Material: MANUSCRIPT_Clean.doc
\end{abstract}




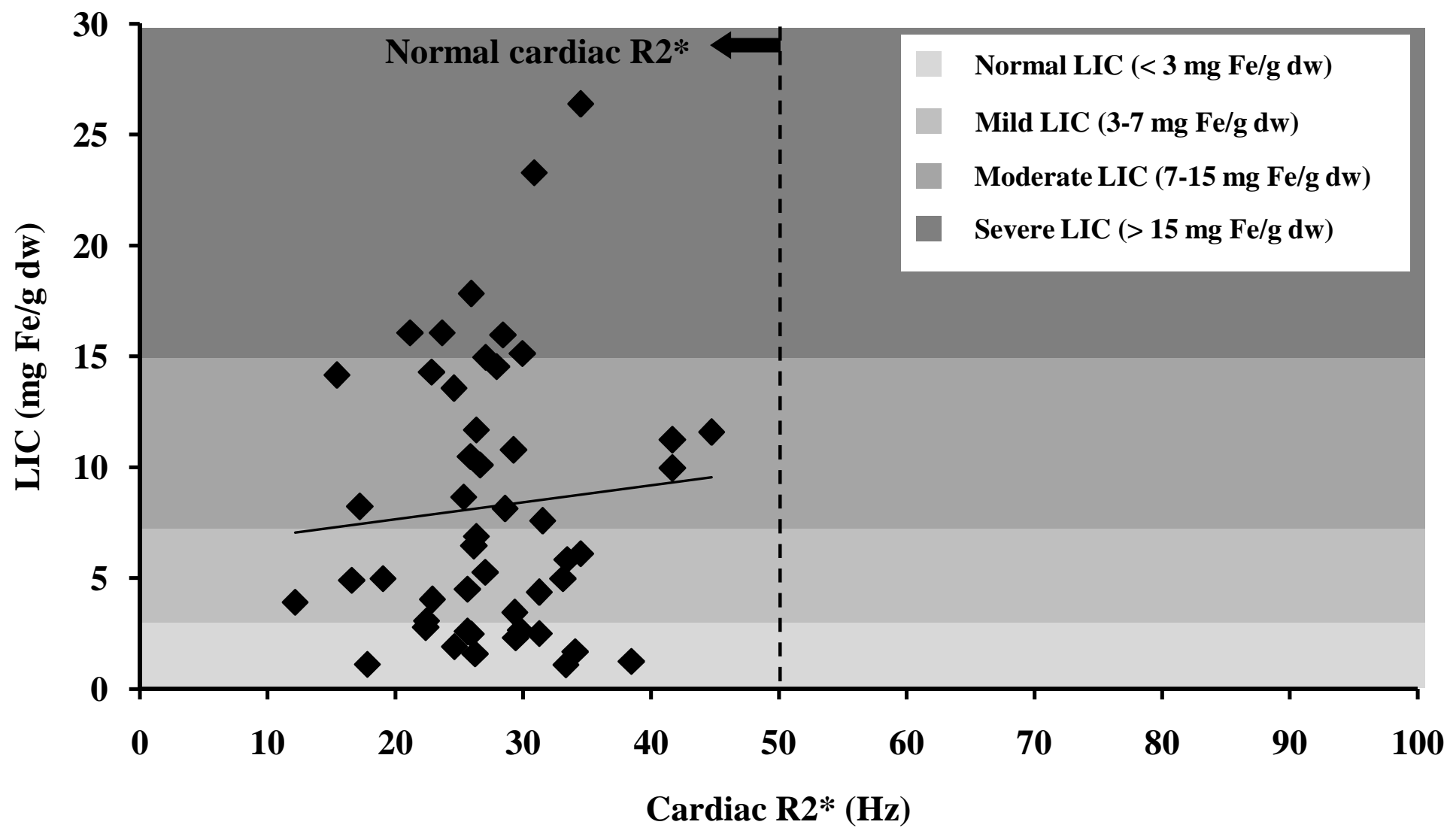

